\title{
Algunos dilemas éticos al investigar población, ciudad y medio ambiente
}

\section{Relatoría de Juan Guillermo Figueroa*}

En el marco de la serie Diálogos y Reflexiones del Centro de Estudios Demográficos, Urbanos y Ambientales (CEDUA) de El Colegio de México, el 28 de mayo de 2010 se organizó una mesa redonda con el tema "Dilemas éticos al investigar población, ciudad y medio ambiente". La coordinación fue de Manuel Ángel Castillo y de Juan Guillermo Figueroa y se buscó que los investigadores invitados compartieran, partiendo de sus respectivas experiencias de trabajo, algunos de los dilemas éticos a los que se han enfrentado en su trayectoria académica, ya sea a título personal o bien por haber sido testigos de éstos.

Nos resultó importante discutir colectivamente qué implica el que en las ciencias sociales no se trabaje tan explícitamente sobre las dimensiones éticas al evaluar proyectos de investigación, a diferencia de lo que ocurre en áreas como la investigación clínica y otras, donde se cuenta con códigos de ética, con comités de ética y además con cursos de ética para los futuros investigadores. Nos preguntamos si serán tan distintos los objetos de estudio y las formas de generar información como para dejar que cada investigador resuelva a título individual los problemas éticos a los que posiblemente se enfrente. En este contexto el objetivo de la sesión fue identificar de manera colectiva algunos elementos potencialmente críticos, desde el punto de vista de la ética, de los procesos de investigación que concentran el interés de los estudios del CEDUA. A manera de ejemplo podemos mencionar: $a$ ) la manipulación de la información (o incluso el dejar de generarla) por razones políticas o de falta de rigor metodológico, $b$ ) los efectos negativos que puede acarrear a los informantes el haber sido identificados de alguna manera por la investigación, $c$ ) la influencia del financiamiento en la definición o en la invisibilización de ciertos temas de investigación, $d$ ) la falta de consensos sobre los compromisos de los investigadores con su población de estudio y, en general, $e$ ) las consecuencias de no evaluar éticamente los proyectos de investigación y de no sensibilizar en estas problemáticas a quienes se forman para ser

* Profesor investigador del Centro de Estudios Demográficos, Urbanos y Ambientales de El Colegio de México. Correo electrónico: jfigue@colmex.mx.

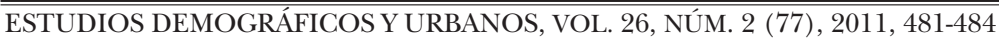


investigadores, entre otras cuestiones asociadas a sus temas específicos de investigación.

Se contó con la participación de un estudioso de la migración (Rodolfo Corona), de alguien dedicado a los estudios urbanos (Gustavo Garza), de una colega que ha investigado sobre sexualidad (Cecilia Gayet), de un compañero que ha elaborado de manera sistemática proyecciones de población en un marco de políticas demográficas (Manuel Ordorica) y finalmente de un colega dedicado al estudio del medio ambiente (José Luis Lezama).

Rodolfo comentó algunos conflictos que podrían presentarse al investigar sobre la migración, por ejemplo en términos del uso no siempre transparente de la información desde la lógica institucional; la subutilización de la información que se genera, e incluso la producción de información que no se necesita dado el conocimiento acumulado; la falta de divulgación de los resultados, y en especial subrayó los silencios discrecionales que se generan ante lo que se ve pero no se nombra o deliberadamente no se investiga.

Gustavo mencionó algunos posibles sesgos estadísticos que se presentan al evaluar proyectos e incluso a los propios estudiantes. En el primer caso se refirió al desarrollo de investigaciones para apoyar proyectos políticos y al riesgo de minimizar las reflexiones conceptuales por atender las urgencias en la planeación gubernamental; mientras que en el segundo caso reflexionó sobre otras opciones para evaluar a los alumnos de la manera más imparcial posible, sin dejar que interfieran los prejuicios o preferencias de la persona dedicada a la docencia. Para terminar desatacó la necesidad de reflexionar sobre los compromisos que tienen con la población quienes investigan.

Cecilia comentó que la investigación sobre sexualidad puede enfrentar a algunos dilemas éticos dado que implica incursionar en temas que corresponden a la intimidad de las personas y en algunos que están socialmente estigmatizados, como el VIH / sida. En ese sentido, mencionó que es necesario asegurar la experiencia del investigador al desarrollar la entrevista y al enfrentar las incertidumbres de quien es entrevistado, así como al cuidar la confidencialidad y al cuestionar el sentido de los derechos de quienes participan en un estudio que a su vez tiene intereses de tipo epidemiológico. Paralelamente aludió a las tensiones que suele vivir la propia persona que hace investigación cuando conoce información que puede remitirla a situaciones conflictivas en su historia personal; incluso hizo referencia a la influencia que tienen las condiciones de vulnerabilidad de una persona en su decisión 
de participar en un proyecto, ya sea porque vive con VIH / sida o por la oferta de alguna compensación por ser parte de un estudio.

$\mathrm{Al}$ comenzar su participación José Luis nos sugirió preguntarnos si lo que investigamos es el ser o el deber ser, ya que de ello derivan horizontes diferentes en nuestros estudios. En ese sentido reflexionó sobre el significado que se le ha ido dando socialmente al "cambio climático" como tema de interés y al proceso de cuestionar las certezas que alimentan las políticas públicas. A continuación sugirió dialogar sobre el uso de la información entre los denominados "tomadores de decisiones", ya que a partir de ello se justifican diferentes tipos de políticas públicas y sus respectivas intervenciones.

Manuel se refirió a un caso en que ciertas proyecciones de población elaboradas por estudiosos de la demografía fueron "ligeramente modificadas" por el presidente del país, sin que cuestionaran a dicho personaje quienes sabían del costo de ese cambio en la estructura poblacional demográfica, precisamente porque se ubicaban en un "contexto presidencialista"; además mencionó otra experiencia en donde la falta de un acuerdo técnico sobre algunos datos demográficos "se resolvió" con la decisión de un secretario de Estado en una situación que el tiempo mostró que no estuvo tan equivocada, aunque fuera tomada por razones políticas más que académicas. Por ello concluyó que se observan tanto lo que denominó el "uso liviano de las estadísticas" como el hecho de que a veces "la política ocupa los huecos que deja la academia”.

Con el propósito de iniciar el debate Juan Guillermo destacó que el propósito de la mesa, más que definir una serie de lineamientos sobre la forma de abordar los dilemas éticos, era dilucidar si los objetos de estudio y las metodologías de las disciplinas son tan diferentes que hacen que unas requieran comités y códigos de ética y otras puedan prescindir de ellos. Advirtió también que se corre el riesgo de que por omisión muchos investigadores no tengan conciencia de los dilemas éticos para prevenirlos e incluso para ser capaces de identificarlos. A manera de ejemplo destacó que la investigación clínica pondera los riesgos y los beneficios de cada investigación antes de llevarla a la práctica, y si bien no son equivalentes las intervenciones de las ciencias sociales, se podría intentar emprender ejercicios análogos con el fin de lograr mayor claridad respecto a las posibles consecuencias positivas y negativas del quehacer de la investigación social. Recordó que alguna vez le cuestionaron qué tipo de investigación era la que se hacía en las ciencias sociales si no pasaba por un filtro de evaluación ética. Se 
podría pensar que cada investigador lo considera de alguna manera, pero él sugirió que era preferible discutir colectivamente qué hacer y cómo abordar algunos de estos dilemas éticos.

En el intercambio de comentarios con los demás asistentes se mencionaron otros temas potencialmente conflictivos que podrían retomarse en debates sobre ética en el entorno de la investigación. Se reconoció la necesidad de divulgar los resultados de las investigaciones y de evidenciar los secretos con que se usa la información a partir de los tipos de financiamiento que se reciben. Se alertó sobre las consecuencias de los actuales criterios de evaluación del quehacer académico y sobre la necesidad de presionar de alguna forma para que se incremente la velocidad en que se publica, aunque a veces no se le dé la misma importancia a dialogar sobre el uso de los resultados. Se propuso reflexionar sobre las diferencias y especificidades de los cuidados éticos en los niveles micro y macro de los estudios y se cuestionó si se requieren comités de ética en este ámbito de investigación. Se recordó que quien funge como asesor de una tesis es corresponsable de la vigilancia ética del proceso de investigación de un estudiante; asimismo puede estimular en sus alumnos la conciencia ética al asumir las consecuencias de todo proceso de investigación. A propósito del entorno de los estudiantes, se preguntó qué instancia sería la más adecuada para fijar las reglas en el contexto de la investigación y de la misma formación de los futuros investigadores, lo cual también aludió a que las relaciones de poder en los espacios académicos son un factor a considerar. Una alumna se refirió a los dilemas que se le presentaron al conocer situaciones potencialmente delictivas cuando elaboraba su tesis, y consideró que podría desempeñarse mejor con el acompañamiento de personas entrenadas en la reflexión ética.

Como cierre de la sesión Juan Guillermo recordó el compromiso que se adquiere formalmente en muchas universidades públicas (como la UNAM) al obtener un título académico: "usar el conocimiento para el bien de la sociedad”. Manuel Ángel subrayó que al investigar ha de tomarse en cuenta la relación entre la ética, el poder y la ideología como referentes teóricos y analíticos que enmarcan el quehacer cotidiano de la investigación.

Esta mesa fue un recordatorio de la diversidad de situaciones que lindan con la ética de la investigación y que no pueden obviarse en el estudio de la población, de la ciudad y del medio ambiente. 